\title{
Evidence synthesis in trial design: an example from the neurosciences
}

\author{
Kieren Egan*, Hanna Vesterinen, Emily Sena, Malcolm Macleod \\ From 2nd Clinical Trials Methodology Conference: Methodology Matters \\ Edinburgh, UK. 18-19 November 2013
}

The increasing prevalence of Alzheimer's disease (AD) poses a considerable socio-economic challenge. Decades of experimental research have not led to the development of effective disease modifying interventions. A deeper understanding of in vivo research might provide insights to inform future in vivo research and trial design. We therefore performed a systematic review and meta-analysis of interventions tested in transgenic mouse models of AD.

We searched electronically for publications testing interventions in transgenic models of $\mathrm{AD}$. We extracted data for outcome, study characteristics and reported study quality and calculated summary estimates of efficacy using random effects meta-analysis.

We identified 427 publications describing 357 interventions in 55 transgenic models, involving 11, 688 animals in 1774 experiments. Of concern (i) reported study quality was relatively low; fewer than 1 in 5 publications reported the blinded assessment of outcome or random allocation to group and no study reported a sample size calculation; (ii) there were few data for any individual interventiononly 16 interventions had outcomes described in 5 or more publications; and (iii) publication bias analyses suggested 1 in 5 pathological and 1 in 7 neurobehavioural experiments remain unpublished. Of the various pathological outcomes reported, neurodegeneration was the best predictor of neurobehavioural outcome $\left(R^{2}=0.72, p<0.01\right)$.

Given these weaknesses in the in vivo modelling of $\mathrm{AD}$ in transgenic animals and the identified risks of bias, clinical trials based on claims of efficacy in animals should only proceed after it has been shown - through systematic review - that those claims are well founded.

University of Edinburgh, Edinburgh, UK
Published: 29 November 2013

doi:10.1186/1745-6215-14-S1-O6

Cite this article as: Egan et al: Evidence synthesis in trial design: an example from the neurosciences. Trials 2013 14(Suppl 1):06.
Submit your next manuscript to BioMed Central and take full advantage of:

- Convenient online submission

- Thorough peer review

- No space constraints or color figure charges

- Immediate publication on acceptance

- Inclusion in PubMed, CAS, Scopus and Google Scholar

- Research which is freely available for redistribution
() Bïomed Central (c) 2013 Egan et al; licensee BioMed Central Ltd. This is an Open Access article distributed under the terms of the Creative Commons Attribution License (http://creativecommons.org/licenses/by/2.0), which permits unrestricted use, distribution, and reproduction in any medium, provided the original work is properly cited. 